Sports Training

\title{
Effects of soccer training during preseason on physical and physiological variables in youth soccer players
}

\author{
Jefferson Fernando Coelho Rodrigues Júnior ${ }^{1,5}$ (D), Carlos Alberto Alves Dias-Filho ${ }^{1,2,3}$ (D), \\ Mário Sevílio de Oliveira Júnior ${ }^{2}$ (D), Carlan da Silva Sena ${ }^{2,3}$ (D), Andressa Coelho Ferreira ${ }^{2,3}$ (D), \\ Thiago Teixeira Mendes ${ }^{5}$ (D), Herikson Araújo Costa ${ }^{1,5}$ (D), \\ Nivaldo de Jesus Silva Soares Junior ${ }^{2,3}$ (D), Raphael Furtado Marques ${ }^{4}$ (D), \\ Cristiano T. Mostarda ${ }^{1,2,3}$ (D), Carlos J. Dias ${ }^{1,3}$ \\ ${ }^{1}$ Universidade Federal do Maranhão, Laboratório de Adaptações Cardiorrenais ao Exercício \\ Físico, Campus Pinheiro, Pinheiro, MA, Brasil; ${ }^{2}$ Universidade Federal do Maranhão, Pinheiro, \\ MA, Brasil; ${ }^{3}$ Universidade Federal do Maranhão, Laboratório de Adaptações Cardiovasculares \\ ao Exercício, São Luís, MA, Brasil; ${ }^{4}$ Centro Universitário Estácio de São Luís, São Luís, Brazil; \\ ${ }^{5}$ Universidade Federal do Maranhão, Núcleo de Estudos e Pesquisas em Atividade Física, \\ Campus Pinheiro, Pinheiro, MA, Brasil.
} Associate Editor: Eduardo Lusa Cadore, Universidade Federal do Rio Grande do Sul, UFRGS,
Porto Alegre, RS, Brasil.

\begin{abstract}
Aim: This study aimed to explore the effects of a training program during the pre-season on aerobic and anaerobic performance, hemodynamics, autonomic variables, and sleep quality in youth soccer players. Methods: Nineteen athletes, with an average age of $17 \pm 1$ years, participated in the study. The multicomponent training protocol was divided into technical, tactical, and physical practice for four weeks. The cardiac autonomic modulation was obtained through an electrocardiogram and blood pressure values were measured by a sphygmomanometer. The athletes answered the Pittsburgh questionnaire that assessed sleep patterns and issues. The $\mathrm{VO}_{\text {max }}^{2}$ was analyzed using the Intermittent Recovery Test Yo-Yo level 1. The RAST test was used to assess anaerobic power. Results: There was improvement in Heart Rate Variability (HRV) indicated by the increase in indexes, mean square root of the differences between normal cycles (RMSSD), low frequency increase (LF) $(p=0.04 ; \mathrm{d}=0.70)$, high frequency decrease (HF) $(p=0.01 ; d=1.02)$ and the LF / HF sympathovagal index $(p=0.03 ; d=0.70)$, variables related to faster recovery. An improvement in the components of sleep duration $(p=0.03)$ and quality $(p=0.02)$ of baseline and post-intervention sleep was also observed. Conclusion: The four-week multicomponent protocol contributed to improving $\mathrm{VO}_{\max }^{2}$, improving fatigue rates, quality of sleep, and maximum power. Additionally, we observe that youth soccer athletes had physiological and hemodynamic adaptations that resulted in an improvement in cardiac autonomic modulation and sleep patterns after four weeks of training.
\end{abstract}

Keywords: physiological stress, sleep quality, autonomic nervous system.

\section{Introduction}

Soccer is one of the most played sports in the world. Many professional teams work in the detection and selection of youth players, pillars in the renewal and maintenance of soccer, enabling these young athletes to develop and become professional athletes ${ }^{1}$. The initiation of youth and children carried out in soccer teams or schools seeks to maximize performance while facilitating early access to the sport increase experience and practice in the sport ${ }^{2}$.

One of the main characteristics of high-performance sports is physical performance. The use of physical tests is important in soccer for detecting players who are physically talented and to serve as a basis for planning appro- priate training regimes for these athletes ${ }^{3}$. Monitoring physical performance during training is essential to assist the development of players and monitoring their evolution ${ }^{4}$.

Soccer is characterized by intermittent efforts carried out at high intensity ${ }^{5,6}$, which requires players to have good technical, tactical, cognitive, and physical performance ${ }^{7}$ from the development of physical fitness variables such as resistance, speed, power, and strength ${ }^{5}$. However, to maintain performance during the game, athletes need to develop greater anaerobic capacity and aerobic recovery capacity ${ }^{8}$. Professionals can monitor athletes' physical performance through different protocols already 
used in soccer. Physiological indices, maximum oxygen consumption $\left(\mathrm{VO}_{\text {max }}^{2} / \mathrm{VO}_{\text {peak }}^{2}\right)$, anaerobic threshold, reduction of fatigue index (FI) can also assist these professionals in designing training 9 .

In a training program, in addition to monitoring physical capacities, it is necessary to monitor variables related to recovery to quantify and plan recovery. Among these measures, heart rate variability (HRV), which improves sleep quality, has been widely used in soccer ${ }^{5,6}$. Physical and recovery capacities are developed mainly in the preseason, a period that precedes competitions between teams ${ }^{10}$. These physical conditions are maintained during the competitive phase and, in the competitive phase, the technical and tactical aspects are emphasized in training ${ }^{10}$.

Recent research shows that FI is directly associated with the ability to perform repeated sprints, as the lower the FI the greater the maintenance and recovery capacity between these sprints. HRV is also associated with the ability to recover after a physical stimulus, being an important tool for prescribing and controlling the training load individually ${ }^{11}$. The increase in HRV correlates positively with the increase in $\mathrm{VO}^{2}{ }_{\text {max }}$, in which an improvement in vagal modulation is observed ${ }^{12}$.

Another aspect that is related to performance is the quality of sleep with a positive impact not only on the physical but also on the cognitive and emotional aspects ${ }^{13}$. When sleep is insufficient, it promotes numerous physiological disorders not only in adults but also in children and adolescents ${ }^{14}$. Despite the knowledge about the presence of sleep disturbances and autonomic dysfunction in many pathologies, little is known about the association of athletes with the Sleep Quality index and autonomic control. Likewise, information about the effects of exercise training on autonomic control and sleep quality is scarce.

Few studies in the literature gathered analyses of several variables of physical performance and recovery in youth soccer athletes. Therefore, this study aimed to evaluate the effects of a training program during the preseason on aerobic and anaerobic performance, hemodynamic, autonomic variables, and sleep quality in youth soccer athletes.

\section{Methods}

\section{Ethical aspects}

All procedures were performed following the ethical principles established in Resolution No. 466, of December 12, 2012, by the National Health Council. The project was approved by the Ethics Committee under number code 51908115.6.0000.5087 and approval $\mathrm{N}^{\mathrm{o}}$. 1.548.709.

\section{Participants}

The study's sample was selected by convenience, composed of 19 youth soccer players, with a mean age of
$17 \pm 1$ years, from a team in northern, Brazil, in preparation for the state championship.

\section{Study design}

The study was carried out during the pre-season. The following evaluations were carried out: (a) Anthropometric assessment (weight, height, and body mass index); (b) Hemodynamic variables at rest (blood pressure and heart rate); (c) Heart Rate Variability; (d) Aerobic and anaerobic power; (f) 1-RM test, (g) Sleep Quality Assessment and (h) Training protocol. All assessments were conducted before the training period (pre-test) and after four weeks of training (post-test).

For the sample calculation, we used the base of 14 soccer teams of the U20 championship, totaling a population of 266 players. In our study, we used 19 athletes in the research.

\section{Hemodynamic variables}

Systolic (SBP) and diastolic (DBP) blood pressure assessments were measured with a sphygmomanometer (Omron digital, Automatic, Hem-7122). The mean arterial pressure (MAP) was obtained through the calculation:

$$
M A P=(2 \times D B P)+S B P \div 3
$$

\section{Heart Rate Variability (HRV)}

Heart rate variability (HRV) was obtained continuously and non-invasively through the electrocardiogram (ECG). The use of the algorithm through the Kubios HRV 2.0 software (Group of Analysis of Biosignals and Medical Images, Kuopio, Finland).

For the evaluation of HRV, a 12-lead electrocardiogram of $600 \mathrm{~Hz}$, of Win Cardio 6.1.1 was used. In this protocol, the subjects were placed in the supine position for $10 \mathrm{~min}$ and remained at rest, with spontaneous and normal respiratory frequency (between 9 and 22 cycles/ $\min )$.

The analysis was performed using the Time Domain and Frequency Domain indices: (a) Time Domain: RR (the average of the RR intervals), SDNN (standard deviation of the RR interval), and RMSSD (square root of the mean squared of the differences between adjacent RR intervals), these were obtained using the Kubios HRV software, version 2.0 (Kubios, Finland); (b) Frequency-domain: The spectral power was integrated into three frequency ranges of interest: High-frequency (HF-0.15-0.4 Hz), Low-frequency (LF-0.04-0.15 Hz) and to assess autonomic balance, the ratio between the two of them (LF/HF). The Fast Fourier transform (FFT) was used to measure the low-frequency band (LF), the high-frequency band (HF), absolute values of power $\left(\mathrm{ms}^{2}\right)$ and standard units $(\mathrm{nu})$, very low frequency (VLF) representing the sympathetic and vagal modulations, respectively, and the LF/HF ratio. 
The HRV analysis in the time domain expresses the results in unit time (milliseconds), measuring each normal RR-interval (sinus beats) during a given time interval and based on statistical methods, the translating indexes of duration fluctuations were calculated.

\section{Evaluation of anaerobic power}

The evaluation of anaerobic potential was performed using the Running anaerobic Sprint Test (RAST). The RAST consists of 6 runs at maximum speed for $35 \mathrm{~m}$, with $10 \mathrm{~s}$ of recovery between runs. For the timing of each maximum stimulus, a set of Speed Test STD photoelectric cells with SPEED TEST 6.0 software from CEFISE was used.

The calculations of maximum, average, minimum power and fatigue index were performed ${ }^{15}$. For analysis purposes, the following times were acquired in each sprint (T1, T2, T3, T4, T5, and T6), the best time (MT), and the average time (TM).

Speed $=$ distance $/$ time.

Acceleration: speed/time.

Power: The power $p(w)$ for each effort was obtained through the product between the athlete's total body mass $(m c(\mathrm{~kg}))$ and the distance of each effort squared $(35 \mathrm{~m})$. The result was divided by the time of each effort $t(\mathrm{~s})=$ raised to the cube.

$$
p(w)=m c \times 35^{2} \div t^{3}
$$

The calculation of the power of the six runs was then determined:

Maximum Power: the highest value.

Minimum Power: the lowest value.

Average Power: the sum of all six power values, divided by six; Fatigue index: (maximum power - minimum power) / total time for the six (6) short distance runs.

\section{Evaluation aerobic power}

The assessment of aerobic power was performed using the Yo-Yo Intermittent Recovery Test Level 1 (YoYo IR 1$)^{16}$. The Yo-Yo IR1 consists of round-trip runs over $20 \mathrm{~m}$ at increasing speeds, interspersed with a 10 -s active recovery period. The speed is controlled by audio signals from a sound player). The test was interrupted when the subject was unable to maintain speed and the distance covered at that point is used for the calculation of $\mathrm{VO}^{2}$ max.

\section{1-RM test}

To evaluate the strength of the participants and to prescribe the intensity of training, the test of one-repetition maximum was applied, in the same exercises used during the session. Before the examination, participants observed the correct demonstration of exercises performed by an experienced professional, to avoid errors in execution during the exercise, and performed a warm-up $(<50 \%$ of estimated maximum load). For the determination of the maximum load, the participants made three to five attempts, with intervals between 3-5 min. The weight was increased, and then a new attempt was made, registering the weight value lifted immediately before a failed attempt.

\section{Training protocol}

The multicomponent training protocol lasted for four weeks and was divided into technical and tactical training, resistance training, interval training in the proportion 1:1 with a focus on aerobic capacity, aerobic treadmill training, and repeated sprint training. Based on the availability of training spaces, weekly training was distributed as follows:

Monday (Power Training) - Exercises: Leg 45, blacksmith squat, leg extension, leg curls, extension chair, adduction, abduction, legless calf. 3 sets of 15 repetitions at $60 \% 1-\mathrm{RM}$, the $45-\mathrm{s}$ interval between sets. The subjects were instructed to perform the movements at maximum speed $^{17}$. After this workout, 20 sprints of $20 \mathrm{~m}$ were performed with $30 \mathrm{~s}$ of rest. Tuesday (Power Training) Volume and intensity of the workout were reduced to improve recovery for ball training the next day. Exercises: leg 45, Smith squat, leg extension, flexing table, adduction, abduction, the calf in the leg. 3 sets of 8 repetitions at $40 \% 1-\mathrm{RM}$, the 60-s interval between sets. After this workout, the athletes ran on the treadmill for $1 \mathrm{~h}$ and $20 \mathrm{~min}$ at a speed of 10 to $12 \mathrm{~km} / \mathrm{h}$. Wednesday, Thursday, and Friday: $1 \mathrm{~h} 30$ of training with the ball: Analytical technical exercises, modified and tactical games. After this workout, participants performed the interval training 1:1. In a field with dimensions of 100 by $50 \mathrm{~m}$, the athletes were positioned in one of the corners of the field (in the corner area) and at the coach's signal, they would perform a lap in $1 \mathrm{~min}$ with $1 \mathrm{~min}$ of passive rest. This was repeated 10 times. At the end workout, the athletes participated in a stretching session.

\section{Workout load control}

In order to quantify the training load, we used the method of subjective perception of effort (SPE) of the session, proposed by Foster et al ${ }^{18}$. Thirty minutes after the end of the training session, the athlete answered the following question: "How was your training session?". The use of the CR10 scale (category-ratio 10) requires some anchoring procedures. The subject indicates a descriptor and then a number from 0 to 10 , which can also be provided in decimals (for example 7.5). The maximum value (10) must be compared to the greatest physical effort performed by the person and the minimum value is the condition of absolute rest ( 0$)$.

The training load based on the SPE product (intensity) for the duration of the session (volume) was expressed in arbitrary units. 


\section{Sleep quality assessment}

Sleep quality was assessed using the Pittsburgh Sleep Quality Index (PSQI), as validated by previous study $^{19}$. The PSQI uses seven components: (1) subjective sleep quality, (2) sleep latency, (3) sleep duration, (4) usual sleep efficiency, (5) sleep disorders, (6) use of medications for sleep, and (7) drowsiness and daytime disturbances during the day.

The score for each component was determined separately, on a score scale ranging from 0 to 21 points, where the higher the score value found, the worse the quality of sleep. Score values between 0 and 4 represent good sleep quality, 5 and 10 represent poor sleep quality, and scores greater than 11 indicate sleep disorders.

\section{Statistical analysis}

Statistical analysis was performed using the GraphPad Prism 8.4.2 software. To assess the normality of the sample, the Shapiro-Wilk test was used, followed by the paired student $\mathrm{t}$-test to compare the moments before and after training. To assess sleep quality, we used the chisquare test. The Pearson's correlation we use in the index of the variable sympathovagal, fatigue index, and $\mathrm{VO}^{2}{ }_{\max }$.

To assess the effect size, we use $d$ Cohen with the following classifications of the effect: small (0.20-0.30), medium (0.40-0.70), and large $(\geq 0.80)$, using the $\mathrm{G}^{*}$ Power3.1.9.4 program. Data are presented as mean \pm standard deviation. $p \leq 0.05$ was considered statistically significant.

\section{Results}

The descriptive and body composition characteristics of the athletes are shown in Table 1. There was no statistical difference between the variables of body mass, height, BMI, maximum power (w), maximum power $(\mathrm{w} / \mathrm{kg})$, Output speed $(\mathrm{m} / \mathrm{s})$, and Output acceleration $\left(\mathrm{m} / \mathrm{s}^{2}\right)$. In addition, we show the differences for relative and absolute fatigue index with a reduction in the pretraining measurements compared to the post $(p=0.0002$ and $p=0.001$ ). As a result, there was an improvement in the distance achieved in the yo-yo test $(p=0.004)$. Additionally, it improved minimum power $(\mathrm{w})(p=0.03)$ and minimum power $(\mathrm{w} / \mathrm{kg})(p=0.008)$ in the pre-training measurement compared to the post.

Table 2 shows the descriptive values in an arbitrary unit on the training load data per week. The responses of pressure and autonomic indexes at the beginning and end of the pre-season are also shown in Table 2. Note that there were significant differences in diastolic blood pressure, RMSSD, LF, HF, and LF/HF ratios. In contrast, the average R-R was decreased.

The results presented in Table 3 show that after the training period there was a reduction in DBP, as well as an improvement in HRV, observed in the significant increase

Table 1 - Anthropometric and performance characteristics of soccer athletes.

\begin{tabular}{|c|c|c|c|c|}
\hline Variables & Baseline $(n=19)$ & Post $(n=19)$ & $p$-value & $d$ \\
\hline Body mass (kg) & $68.28 \pm 6.78$ & $69.0 \pm 7.0$ & 0.13 & 0.10 \\
\hline Height (m) & $1.7 \pm 0.6$ & $1.7 \pm 0.6$ & 1.00 & 0.00 \\
\hline Body mass index $\left(\mathrm{kg} \cdot \mathrm{m}^{2}{ }^{2}\right)$ & $22.2 \pm 2.3$ & $22.2 \pm 2.5$ & 0.98 & 0.00 \\
\hline Distance yo-yo test (m) & $814.70 \pm 385.4$ & $1000 \pm 325.5$ & 004 & 0.57 \\
\hline Fatigue index $\left(\mathrm{w} \cdot \mathrm{kg}^{-1}\right)$ & $7.15 \pm 3.1$ & $4.18 \pm 0.9$ & 0.001 & 1.03 \\
\hline Minimum power absolute (w) & $41.22 \pm 8.8$ & $28.42 \pm 8.4$ & 0.0002 & 1.58 \\
\hline Minimum power relative (w/kg) & $4.78 \pm 0.4$ & $5.77 \pm 1.3$ & 0.008 & 0.86 \\
\hline Medium power absolute (w) & $438.95 \pm 88.7$ & $445.45 \pm 111.5$ & 0.42 & 0.06 \\
\hline Medium power relative (w/kg) & $6.71 \pm 1.3$ & $7.01 \pm 1.2$ & 0.23 & 0.22 \\
\hline Maximum power (w) & $586.68 \pm 118.7$ & $548.21 \pm 126.4$ & 0.20 & 0.30 \\
\hline Output speed $(\mathrm{m} / \mathrm{s})$ & $5.79 \pm 0.1$ & $5.36 \pm 1.6$ & 0.06 & 0.27 \\
\hline Output acceleration $\left(\mathrm{m} / \mathrm{s}^{2}\right)$ & $1.03 \pm 0.0$ & $0.96 \pm 0.2$ & 0.33 & 0.36 \\
\hline
\end{tabular}

$d=\mathrm{d}$ de Cohen; $p$ significant $>0.05$.

Table 2 - Descriptive statistics (M [95\% CI]) of training load data per week.

\begin{tabular}{lcccc}
\hline Variables & Week-1 & Week-2 & Week-3 & Week-4 \\
\hline RPE (CR-10) & $9.49[8.43-10.55]$ & $8.06[6.97-9.16]$ & $7.98[6.96-8.99]$ & $7.55[6.60-8.51]$ \\
Internal Load (U.A) & $1.043[898.49-1.120 .49]$ & $886.6[620.09-963.31]$ & $877.8[656.09-997.31]$ & $830.05[534.26-916.25]$ \\
\hline
\end{tabular}

RPE: the rating of perceived exertion; CR-10: Category-ratio10; Statistically different from Week-1; Week-2; Week-3; and Week-4, for a $p<0.05$. U.A. Arbitrary units. 
Table 3 - Values of blood pressure, autonomic indexes, mean (SD) at the beginning and end of the preseason.

\begin{tabular}{lcccc}
\hline Variables & Baseline $(\mathbf{n}=\mathbf{1 9})$ & Post $(\mathbf{n}=\mathbf{1 9})$ & $\boldsymbol{p}$-value & $\boldsymbol{d}$ \\
\hline \multicolumn{5}{c}{ Hemodynamic } \\
HR (bpm) & $72.0 \pm 12.7$ & $73.2 \pm 11.2$ & 0.34 & 0.00 \\
SBP (mmHg) & $124.1 \pm 12.4$ & $123.0 \pm 14.5$ & 0.31 & 0.08 \\
DBP (mmHg) & $66.7 \pm 9.4$ & $62.6 \pm 7.4$ & $0.05^{*}$ & 0.47 \\
MBP (mmHg) & $85.8 \pm 8.4$ & $82.8 \pm 8.9$ & 0.06 & 0.37 \\
\multicolumn{5}{c}{ Time domain } \\
RR (ms) & $918.55 \pm 98.75$ & $894.76 \pm 87.82$ & 0.11 & 0.25 \\
SDNN (ms) & $77.4 \pm 32.7$ & $80.5 \pm 33.8$ & 0.28 & 0.09 \\
RMSSD (ms) & $67.0 \pm 37.3$ & $79.6 \pm 57.7$ & $0.04^{*}$ & 0.24 \\
& \multicolumn{2}{c}{ Frequency domain } \\
LF (ms $\left.{ }^{2}\right)$ & $1870.0 \pm 143.0$ & $2370.0 \pm 913.0$ & 0.10 & 0.39 \\
LF (nu) & $47.5 \pm 15.7$ & $36.1 \pm 16.5$ & $0.04^{*}$ & 0.70 \\
HF (ms $\left.{ }^{2}\right)$ & $2340.0 \pm 198.0$ & $5080.0 \pm 303.0$ & $0.01^{*}$ & 1.02 \\
HF (nu) & $52.4 \pm 15.7$ & $63.8 \pm 16.5$ & $0.04^{*}$ & 0.70 \\
LF/HF & $1.1 \pm 0.7$ & $0.67 \pm 0.43$ & $0.03^{*}$ & 0.70 \\
\hline
\end{tabular}

Data are: SBP, systolic blood pressure; DBP, diastolic blood pressure; MBP, mean blood pressure; HR, heart rate; RR, interval means; SDNN, the standard deviation of the intervals; RMSSD, root mean square successive difference of the RR intervals; LF, low-frequency spectrum; HF, high-frequency spectrum; LF/HF, sympathovagal balance. *Significant difference Baseline vs Post $(\mathrm{p}<0.05)$. in the indexes (RMSSD, HF) and reduction (LF and LF/ HF indexes).

Sleep quality in athletes' groups evaluated by Pittsburgh Sleep Quality Score presented alterations in the components of sleep duration $(p=0.03)$ and quality $(p=0.02)$ of pre- and post-intervention sleep (Table 4$)$.

Figure 1 shows the results regarding changes in test performance during the period under investigation. There was a significant difference in maximal oxygen uptake $(p<0.001)$ and in the absolute fatigue index $(p<0.01)$. However, there was no difference in the relative fatigue index. There was an improvement in performance in the Yo-Yo IR1 combined with a better fatigue index, which also reflects a speed improvement when comparing the pre-and post-assessments of the preseason.

Figure 2 shows the correlation between $\mathrm{VO}^{2}{ }_{\text {max }}$ and sympathovagal balance and $\mathrm{VO}^{2}{ }_{\text {max }}$ and the fatigue index. The findings show a positive correlation with fatigue index and sympathovagal balance, and a negative crelationship between $\mathrm{VO}_{\text {max }}^{2}$ with sympathovagal balance in youth athletes at the end of the pre-season.

\section{Discussion}

The study aimed to analyse the performance responses and to verify if the cardiac autonomic modulation at

Table 4 - Sleep quality in athletes' groups evaluated by Pittsburgh Sleep Quality Score.

\begin{tabular}{|c|c|c|c|c|c|c|}
\hline & \multirow[t]{2}{*}{ Category } & \multicolumn{2}{|c|}{ Baseline $(n=19)$} & \multicolumn{2}{|c|}{ Post $(n=19)$} & \multirow[t]{2}{*}{ p-value } \\
\hline & & Absolute & Relative & Absolute & Relative & \\
\hline \multirow[t]{4}{*}{ Subjective Sleep Quality } & Very good & 2 & 10.52 & 7 & 36.85 & 0.11 \\
\hline & Good & 16 & 84.21 & 12 & 63.15 & \\
\hline & $\mathrm{Bad}$ & 1 & 5.27 & 0 & 0 & \\
\hline & Very bad & 0 & 0 & 0 & 0 & \\
\hline \multirow[t]{4}{*}{ Sleep Latency (Min) } & $\leq 15 \mathrm{~min}$ & 13 & 68.42 & 15 & 78.96 & 0.20 \\
\hline & 16 a $30 \mathrm{~min}$ & 5 & 26.31 & 2 & 10.52 & \\
\hline & 31 a $60 \min$ & 1 & 5.26 & 2 & 10.52 & \\
\hline & $>60 \mathrm{~min}$ & 3 & 15.78 & 0 & 0 & \\
\hline \multirow[t]{4}{*}{ Duration of Sleep (Hours) } & $>7$ & 15 & 78.94 & 19 & 100 & 0.03 \\
\hline & $6-7$ & 4 & 21.06 & 0 & 0 & \\
\hline & $5-6$ & 0 & 0 & 0 & 0 & \\
\hline & $<5$ & 0 & 0 & 0 & 0 & \\
\hline \multirow[t]{4}{*}{ Sleep Efficiency (\%) } & $>85$ & 17 & 89.48 & 19 & 100 & 0.14 \\
\hline & $75-84$ & 2 & 10.52 & 0 & 0 & \\
\hline & $65-74$ & 0 & 0 & 0 & 0 & \\
\hline & $<65$ & 0 & 0 & 0 & 0 & \\
\hline \multirow[t]{4}{*}{ Sleep Disorders (Events/Weeks) } & None & 0 & 0 & 0 & 0 & 1.00 \\
\hline & $<1$ & 0 & 0 & 0 & 0 & \\
\hline & $1-2$ & 19 & 100 & 19 & 0 & \\
\hline & 3 & 0 & 0 & 0 & 0 & \\
\hline
\end{tabular}


Table 4 - continued

\begin{tabular}{|c|c|c|c|c|c|c|}
\hline & \multirow[t]{2}{*}{ Category } & \multicolumn{2}{|c|}{ Baseline $(n=19)$} & \multicolumn{2}{|c|}{ Post $(n=19)$} & \multirow[t]{2}{*}{ p-value } \\
\hline & & Absolute & Relative & Absolute & Relative & \\
\hline \multirow[t]{4}{*}{ Use of Sleeping Medication (Events/Weeks) } & None & 19 & 100 & 19 & 100 & 1.00 \\
\hline & $<1$ & 0 & 0 & 0 & 0 & \\
\hline & $1-2$ & 0 & 0 & 0 & 0 & \\
\hline & 3 & 0 & 0 & 0 & 0 & \\
\hline \multirow[t]{4}{*}{ Daytime Sleepiness } & None & 12 & 63.17 & 13 & 68.42 & 0.13 \\
\hline & Small & 2 & 10.52 & 5 & 26.31 & \\
\hline & Moderate & 5 & 26.31 & 1 & 5.26 & \\
\hline & High & 0 & 0 & 0 & & \\
\hline \multirow[t]{3}{*}{ Sleep Quality } & Good (0-4) & 11 & 57.90 & 17 & 89.48 & 0.02 \\
\hline & $\operatorname{Bad}(5-10)$ & 8 & 42.10 & 2 & 10.52 & \\
\hline & Disturb (> 10) & 0 & 0 & 0 & 0 & \\
\hline
\end{tabular}

Results are presented by distribution frequency and relative percentage, Chi-square test.

rest and the quality of sleep had an association with improvement in the performance of youth soccer athletes during the pre-season training. The main finding of this study was an association between cardiac autonomic modulation and the improvement in $\mathrm{VO}_{\text {max }}^{2}$ and reduction in fatigue index. The four-week multicomponent protocol contributed to the improvement of $\mathrm{VO}^{2}{ }_{\max }$, improvement of fatigue indices, quality of sleep, and maximum power. Additionally, there was an improvement in cardiac autonomic modulation, evidenced by the increase in vagal modulation.

During the preparatory period, we observed that the athletes in this study obtained cardiovascular benefits, such as maintaining blood pressure levels, as in other studies performed with aerobic and resistance exercises ${ }^{20}$ that describe a reduction in systolic, diastolic, and mean pressure in post-training. However, this effect is more evident in hypertensive patients ${ }^{21}$.

Previous studies show a relationship between improvement in vagal modulation and $\mathrm{VO}_{\text {max }}^{2}$ either in sedentary individuals $\mathrm{s}^{22}$ or athletes ${ }^{23}$. Our findings corro- borate with Oliveira et al. ${ }^{24}$ who observed a positive association between vagal modulation variables and aerobic performance in professional soccer players after 6 weeks of training.

In addition to the improvement in $\mathrm{VO}_{\text {max }}^{2}$, we can observe a reduction of the relative and absolute fatigue index. According to Bangsbo (1998) ${ }^{16}$, for the classification of the fatigue index, at the end of the pre-season, the participants with excellent fatigue index $(<6.96 \mathrm{w} / \mathrm{s})$ increased from $60 \%$ to $100 \%$. From the fatigue index, it is possible to quantify the athlete's ability to withstand successive stimuli at high intensity, minimizing the reduction in performance ${ }^{25}$.

Despite the improvement in the fatigue index, four weeks of training were not enough to improve anaerobic power. In his study with elite athletes, Lopes et al. (2005) did not observe an improvement in speed after 10 weeks of training ${ }^{26}$.

According to Gomes (2002) it takes at least 3 months for the development of anaerobic power to be observed. Thus, the training period used in the present
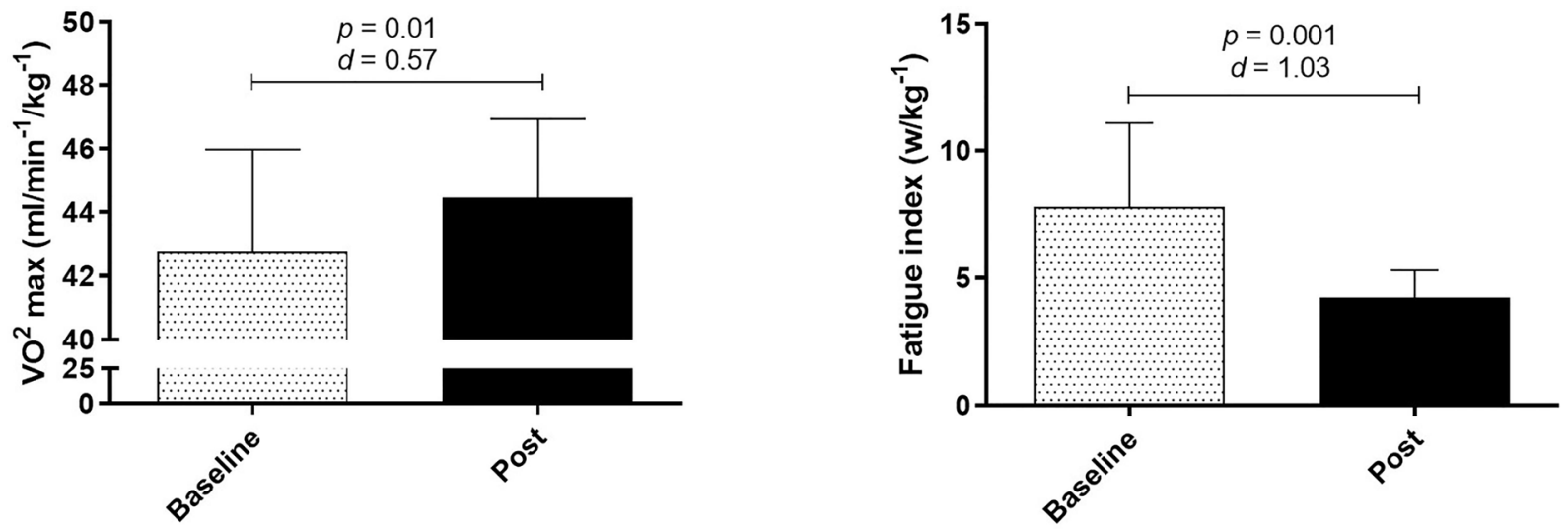

Figure 1 - Values obtained in performance tests expressed as mean (SD) at the baseline and post of the pre-season. $\mathrm{VO}^{2}{ }_{\max }\left(\mathrm{mL}^{\mathrm{kg}} \mathrm{kg}^{-1} \cdot \mathrm{min}{ }^{-1}\right)$, oxygen consumption in a maximal stress test. 

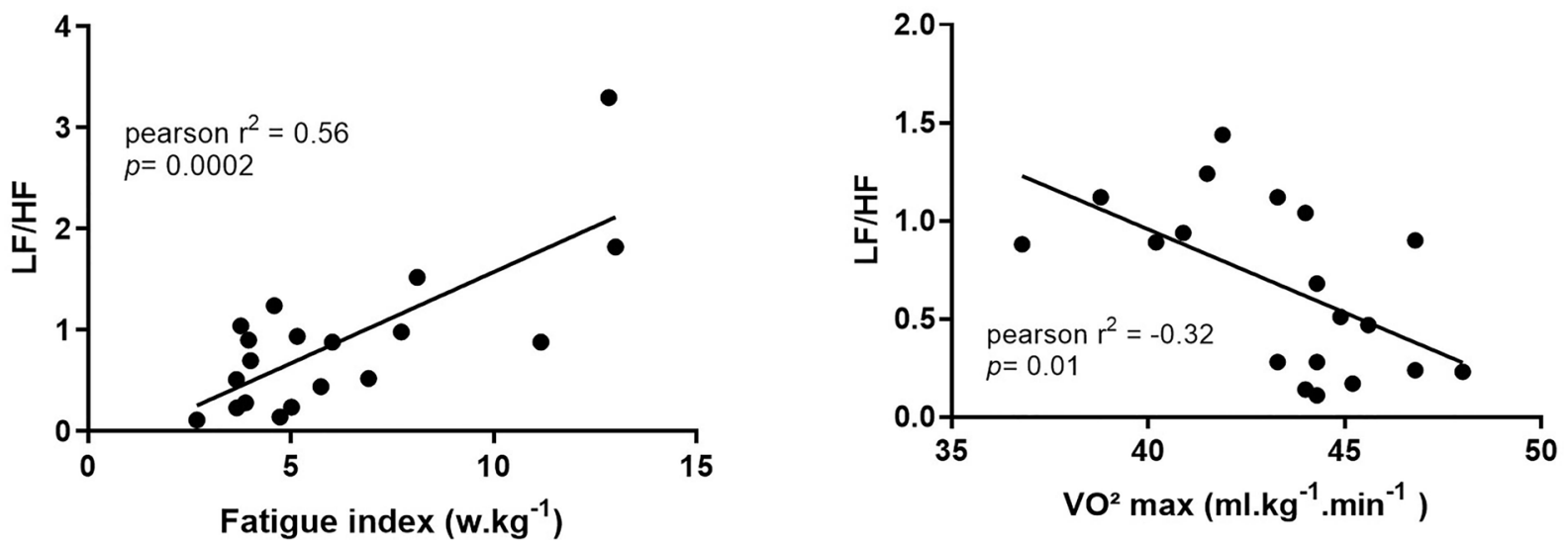

Figure 2 - Pearson's correlation between sympathovagal and $\mathrm{VO}^{2}$ max balance, and sympathovagal balance and fatigue index in youth athletes at the end of the pre-season; $d=\mathrm{d}$ de Cohen; $p$ significant $>0.05$.

study may not have been the most suitable for assessing anaerobic power ${ }^{27}$. This explains the discrepancy in the improvement of anaerobic power with the autonomic variables, which in general present adaptations more quickly $^{28}$. Levy et al. (1998) suggest that the improvement of autonomic variables does not depend on age $\mathrm{e}^{29}$.

Our results of maximum, medium, and minimum power are inferior when compared to other studies ${ }^{30,31}$. This can be explained by these studies being conducted with elite players.

Some factors such as age and level of training can influence the fatigue index. When comparing juveniles with professionals, observed lower fatigue rates in professional players ${ }^{32}$.

We observed a correlation between the sympathovagal balance and the variables of aerobic and anaerobic performance. There was a significant correlation between $\mathrm{VO}^{2}$ max and fatigue index. The sympathovagal balance showed a moderate inverse correlation with $\mathrm{VO}^{2}{ }_{\text {max }}$ and directly proportional to the fatigue index, which can be explained by lower sympathetic activity. Studies show that autonomic modulation, both at rest and during exercise, increases when a positive adaptation to training occurs $^{22,33}$, leading to an improvement in physical performance ${ }^{11}$. Corroborating with our findings, after four weeks of training, an improvement in cardiac autonomic modulation was observed both in the time domain and in the frequency domain, variables that reflect an improvement in vagal modulation and a reduction in sympathetic activity, factors that are decisive for faster recovery.

Prolonged periods of sleep deprivation are associated with an autonomic imbalance, due to an increase in sympathetic activity compared to the parasympathetic component $^{34}$. Further, our findings indicate that in addition to improving performance, there was a better balance between autonomic systems and consequently, in sleep pattern, factors associated with improved physical performance.
When comparing the pre-and post-training measurements during the pre-season, there was a quantitative and qualitative improvement in the sleep of athletes. A better sleep pattern is indispensable for athletes, which directly improves performance while minimizing the chances of injuries $^{35}$.

Despite the perceived importance of sleep by athletes, they still encounter difficulties in maintaining a good sleep pattern due to routine, which may affect performance ${ }^{36}$. In our study, although there was an improvement in sleep pattern, the athletes still presented values below those recommended. In a previous study, Milewski et al. ${ }^{37}$ observed how adolescents that sleepless $(<8 \mathrm{~h})$ are 1.7 times more likely to be injured when compared with athletes who sleep more.

This study was important because it demonstrated the effects of a four-week training program in restoring cardiac autonomic balance, cardiovascular risk, sleep quality, and physical performance of soccer players. This study can be a useful tool for coaches and athletes for the evaluation of physical performance. The application of physical tests on youth players at the beginning of the season may serve as a basis for coaches for developing better periodization, which is related to an improvement in aerobic performance and parameters related to recovery, a determining factor for the improvement of long-term performance. In addition, aerobic performance and parameters related to recovery minimize the chances of stress injuries.

Limitations of this study include the number of participants and lack of daily monitoring of the internal training load, which would better control daily training intensity ${ }^{38}$.

\section{Conclusion}

The four-week multicomponent protocol contributed to improving $\mathrm{VO}^{2}$ max , improving fatigue rates, quality of 
sleep, and maximum power. Additionally, we observe that youth soccer athletes had physiological and hemodynamic adaptations that resulted in an improvement in cardiac autonomic modulation and sleep patterns after four weeks of training.

\section{References}

1. Buchheit M, Mendez-Villanueva A, Simpson BM, Bourdon PC. Match running performance and fitness in youth soccer. Int J Sports Med. 2010;31:818-25.

2. Post EG, Bell DR, Trigsted SM, Pfaller AY, Hetzel SJ, Brooks MA, et al. Association of competition volume, club sports, and sport specialization with sex and lower extremity injury history in high school athletes. Sports Health. 2017;9:518-23.

3. Impellizzeri, F. M. Marcora SM, Castagna C, Reilly T, Sassi A, Iaia FM, et al. Physiological and performance effects of generic versus specific aerobic training in soccer players. Int J Sports Med. 2006;27: 483-92.

4. Vieira LHP, Carling C, Barbieri FA, Aquino R., Santiago PRP. Match running performance in young soccer players: A systematic review. Sports Med. 2019;49:289-318.

5. Iaia FM, Ermanno R, Bangsbo J. High-intensity training in football. Int J Sports Physiol Perform. 2009;4:291-306.

6. Iellamo F, Legramante JM, Pigozzi F, Spataro A, Norbiato $\mathrm{G}$, Lucini $\mathrm{D}$, et al. Conversion from vagal to sympathetic predominance with strenuous training in high-performance world-class athletes. Circulation. 2002;105:2719-24.

7. Praça GM, Morales JCP, Greco PJ. Demandas físicas, fisiológicas, táticas e técnicas no pequeno jogo 3vs. 3 no futebol: uma revisão sistemática. Rev Bras Ciência Mov. 2017;25:141-52.

8. Sousa RB, Praça GM, Greco JP. Avaliação de jogadores de futebol: relação entre a capacidade aeróbica e eficácia tática. RBFF-Revista Bras Futsal Futeb. 2017;9:190-6.

9. Pasquarelli BN, Souza V, Stanganelli LCR. Os jogos com campo reduzido no futebol. Braz J Soccer Sci. 2013;3:2-27.

10. Gonaus C, Birklbauer J, Lindinger SJ, Stöggl TL, Müller E. Changes over a decade in anthropometry and fitness of elite Austrian youth soccer players. Front Physiol. 2019;10:333.

11. Bellenger CR, Fuller JT, Thomson RL, Davison K, Robertson EY, Buckley JD. Monitoring athletic training status through autonomic heart rate regulation: a systematic review and meta-analysis. Sports Med. 2016;46:1461-86.

12. Boullosa DA, Abreu L, Nakamura FY, Muñoz VE, Domínguez E, Leicht AS. Cardiac autonomic adaptations in elite Spanish soccer players during preseason. Int J Sports Physiol Perform. 2013;8(4):400-9.

13. Bonnar D, Bartel K, Kakoschke N, Lang C. Sleep interventions designed to improve athletic performance and recovery: a systematic review of current approaches. Sports Med. 2018;48:683-703.

14. Owens JA, Weiss MR. Insufficient sleep in adolescents: causes and consequences. Minerva Pediatr. 2017;69:326-36.

15. Zagato AM, Beck WR, Gobatto CA. Validity of the running anaerobic sprint test for assessing anaerobic power and predicting short-distance performances. J Strength Cond Res. 2009;23:1820-7.
16. Bangsbo J. Quantification of anaerobic energy production during intense exercise. Med Sci Sports Exerc. 1998;30:4752.

17. Lamas L, Batista MA, Fonseca R, Piveti B, Tricoli V. Treinamento de potência muscular para membros inferiores: número ideal de repetições em função da intensidade e densidade da carga. J Phys Educ. 2010;21:263-70.

18. McGuigan MR, Foster C. A new approach to monitoring resistance training. Strength Cond J. 2004;25:23-5.

19. Bertolazi AN, Fagondes SC, Hoff LS, Dartora EG, Miozzo IC, de Barba ME, et al. Validation of the Brazilian Portuguese version of the Pittsburgh Sleep Quality Index. Sleep Med. 2011;12(1):70-5.

20. Polito MD, Farinatti PTV. Respostas de frequência cardíaca, pressão arterial e duplo-produto ao exercício contra-resistência: uma revisão da literatura. Rev Port Ciências Desporto. 2003;3:79-91.

21. Brum PC, Forjaz CL., Tinucci T, Negrão CE. Adaptações agudas e crônicas do exercício físico no sistema cardiovascular. Rev Paul Educ Fís. 2004;18:21-31.

22. Hautala AJ. Effect of physical exercise on autonomic regulation of heart rate. (2002).

23. Hedelin R, Bjerle P, Henriksson-Larsen K. Heart rate variability in athletes: relationship with central and peripheral performance. Med Sci Sports Exerc. 2001;33:1394-8.

24. Oliveira RS, Pedro RE, Milanez VF, Bortolotti H, VitorCosta M, Nakamura F. Relação entre variabilidade da frequência cardíaca e aumento no desempenho físico em jogadores de futebol. Rev Bras Cineantrop Desemp Hum. 2012;14:713-22.

25. Araújo KS, Santos D, Costa LR, Castro EA, Pimenta CE, Raiz LMM, et al. Influência de diferentes sistemas táticos sobre a intensidade de esforço e a fadiga de jogadores de futebol da categoria sub-17. RBFF-Revista Bras Futsal Futeb. 2019;11:172-8.

26. Lopes CR. Análise das capacidades de resistência, força e velocidade na periodização de modalidades intermitentes. (2005).

27. Gomes AC. Treinamento desportivo: estruturação e periodização. Porto Alegre: Artmed, 2002.

28. Maciel BC, Marin-Neto JÁ, Martins LE. Sympathetic and parasympathetic changes in heart rate control during dynamic exercise-induced by endurance training in man. Braz J Med Biol Res. 1989;22:631-43.

29. Levy WC, Cerqueira MD, Harp GD, Johannessen KA, Abrass IB, Schwartz RS, et al. Effect of endurance exercise training on heart rate variability at rest in healthy young and older men. Am J Cardiol. 1998;82(10):1236-41.

30. Spigolon LMP, Borin JP, Leite GS, Padovani CRP, Padovani CR. Potência anaeróbia em atletas de futebol de campo: diferenças entre categorias. Coleção Pesq Educ Fis. 2007;6:421-8.

31. Santos D, Coledam DC, $\backslash$ dos-Santos J. Alterações na potência anaeróbia após a pré-temporada em atletas profissionais de futebol. Mov. e Percepção 2009;10.

32. Pellegrinotti IL, Daniel JF, Cielo FBL, Cavaglieri CR, Neto JB, Montebelo MI, et al. Análise da potência anaeróbia de jogadores de futebol de três categorias, por meio do "teste 
de velocidade para potência anaeróbia"(TVPA) do running based anaerobic sprint test (rast). Arq Mov. 2008;4:3-15.

33. Mourot, L., Bouhaddi, M., Perrey, S., Rouillon, J.-D. \& Regnard, J. Quantitative Poincare plot analysis of heart rate variability: effect of endurance training. Eur J Appl Physiol. 2004;91:79-87.

34. Charest J, Grandner MA. Sleep and athletic performance: impacts on physical performance, mental performance, injury risk and recovery, and mental health. Sleep Med Clin. 2020;15:41-57.

35. Watson AM. Sleep and athletic performance. Curr Sports Med Rep. 2017;16:413-18.

36. Mah CD. Mah KE, Kezirian EJ, Dement WC. The effects of sleep extension on the athletic performance of collegiate basketball players. Sleep 2011;34:943-50.

37. Milewski MD, Skaggs DL, Bishop GA, Pace JL, Ibrahim DA, Wren TA, et al. Chronic lack of sleep is associated with increased sports injuries in adolescent athletes. J Pediatr Orthop. 2014;34(2):129-33.
38. Pedro RE, Milanez VF, Boullosa DA, Nakamura FY. Running speeds at ventilatory threshold and maximal oxygen consumption discriminate futsal competitive level. $J$ Strength Cond Res. 2013;27:514-8.

\section{Corresponding author}

Carlos José Dias, Estrada de pacas, km10 s/n, Pinheiro, MA, Brazil.

E-mail: carlosdias.ef@gmail.com.

Manuscript received on January 13, 2021

Manuscript accepted on April 29, 2021

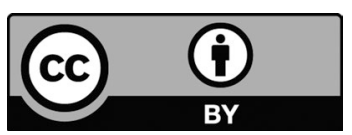

Motriz. The Journal of Physical Education. UNESP. Rio Claro, SP, Brazil - eISSN: 1980-6574 - under a license Creative Commons - Version 4.0 